\title{
PENGARUH BIMBINGAN BELAJAR DI LUAR SEKOLAH TERHADAP HASIL BELAJAR MATEMATIKA SISWA KELAS IV SDN SEKECAMATAN PEJAGOAN TAHUN AJARAN 2019/2020
}

\author{
Siti Rahmawati ${ }^{1}$, Joharman², Ngatman ${ }^{3}$ \\ Sebelas Maret University \\ sitirahmawati@student.uns.ac.id
}

\section{Article History accepted 01/10/2020}

approved 01/11/2020 published 01/12/2020

\begin{abstract}
The study aimed to prove the difference between students taking tuition and students who did not take tuition on mathematics learning outcomes of fourth grade students in public elementary schools at Pejagoan sub-district in academic year of 2019/2020. The research was quantitative comparative method. Type of sampling was cluster random sampling technique with the help of Statistical Product and Service Solution (SPSS) version 16. The samples were 263 students in ten public elementary schools at Pejagoan sub-district. Data analysis used independent sample t-test, with a significance level of 0.05 . The results of the analysis show that there is a significant difference between students who take tutoring outside of school and students who do not take tutoring outside of school on student mathematics learning outcomes with a known significance value of 0.000 (sig <0.005).
\end{abstract}

Keywords: tuition, mathematics learning outcomes

\begin{abstract}
Abstrak: Penelitian ini bertujuan untuk membuktikan adanya perbedaan antara siswa yang mengikuti bimbingan belajar di luar sekolah dengan siswa yang tidak mengikuti bimbingan belajar di luar sekolah terhadap hasil belajar matematika siswa kelas IV SDN se-Kecamatan Pejagoan tahun ajaran 2019/2020.Penelitian ini merupakan penelitian kuantitatif dengan metode komparasi. Pengambilan sampel dilakukan dengan teknik cluster random sampling dengan bantuan aplikasi Statistical Product and Serice Solution (SPSS) versi 16. Jumlah sampel dalam penelitian ini yaitu 263 siswa di sepuluh SDN se-Kecamatan Pejagoan. Pengambilan data menggunakan tes. Analisis data menggunakan uji t independent sample $t$ test, dengan taraf signifikansi 0,05 . Hasil analisis menunjukkan bahwa ada perbedaan signifikan antara siswa yang mengikuti bimbingan belajar di luar sekolah dengan siswa yang tidak mengikuti bimbingan belajar di luar sekolah terhadap hasil belajar matematika siswa dengan diketahui nilai signifikansi adalah $0,000(\mathrm{sig}<0,005)$.
\end{abstract}

Kata Kunci: Bimbingan Belajar di Luar Sekolah, Hasil Belajar Matematika

This work is licensed under a Creative Commons Attribution-ShareAlike 4.0 International License. 


\section{PENDAHULUAN}

Pendidikan memegang peranan penting untuk mengembangkan kualitas sumber daya manusia sehingga mampu berkompetensi dalam perkembangan ilmu pengetahuan dan teknologi (iptek). Pendidikan harus dilaksanakan sebaik-baiknya disertai dukungan dari pemerintah, guru, orang tua siswa dan masyarakat yang turut serta dalam rangka meningkatkan mutu pendidikan.

Salah satu syarat yang harus dipenuhi agar proses pembelajaran dapat terjadi dan berjalan dengan baik adalah adanya bimbingan belajar di luar sekolah. Hal ini tidak dapat dilepaskan dari karakteristik peserta didik dan permasalahan-permasalahan belajar yang selalu ada. Beberapa contoh permasalahan belajar diantaranya kebiasaan belajar yang buruk, waktu belajar yang kurang disiplin, kesulitan membuat catatan, dan yang terutama kesulitan siswa dalam memahami materi matematika. Kesulitan-kesulitan itulah yang melatar belakangi perlunya bimbingan belajar. Artinya, proses belajar tidak dapat berjalan tanpa proses bimbingan. Bimbingan belajar adalah suatu bantuan yang diberikan pada peserta didik untuk mengatasi masalah-masalah dalam belajar sehingga mendapat hasil yang baik (Prasetya, Winarno \& Eriany, 2013:2). Dengan adanya bimbingan belajar memiliki kemungkinan lebih besar agar siswa mencapai tujuan belajarnya secara lebih optimal sebagaimana yang diharapkan.

Pemerintah memberikan solusi bagi siswa yang ingin melakukan bimbingan belajar di luar sekolah untuk membantu mengatasi kesulitan belajar dan mendukung memaksimalkan hasil belajar siswa yaitu adanya pendidikan nonformal sesuai dengan UU Sisdiknas No. 20 tahun 2003 (Sisdiknas, 2011: 4) menyatakan bahwa:

Pendidikan nonformal adalah pendidikan yang teratur dengan sadar dilakukan tetapi tidak terlalu mengikuti peraturan-peraturan yang tetap dan ketat. Pendidikan nonformal diselenggarakan bagi warga masyarakat yang memerlukan layanan pendidikan yang berfungsi sebagai pengganti, penambah, dan/atau pelengkap pendidikan formal dalam rangka mendukung pendidikan sepanjang hayat.

Salah satu pendidikan nonformal yang memberikan bimbingan belajar kepada siswa adalah lembaga bimbingan belajar di luar sekolah. Lembaga bimbingan belajar di luar sekolah memberikan layanan jasa pendidikan berupa menambah frekuensi belajar yang bertujuan untuk meningkatkan prestasi akademik siswa (Nusantari, 2011: 17). Menurut Kartadinata (Nurlinggasari, 2017:2) dengan mengikuti bimbingan belajar siswa dapat mengatasi masalah-masalah yang dihadapinya dalam belajar sehingga setelah melalui proses belajar mereka dapat meningkatkan hasil belajar yang optimal sesuai dengan kemampuan yang dimiliki.

Layanan bimbingan belajar di luar sekolah diselenggarakan untuk membantu siswa dalam menghadapi dan menyelesaikan berbagai macam permasalahan belajar yang ada. Bimbingan belajar di luar sekolah membahas materi-materi yang rata-rata masih belum dipahami oleh siswa. Bimbingan belajar di luar sekolah dilakukan dengan pemilihan metode dan strategi yang tepat dan menarik. Hal ini dilakukan agar semua permasalahan siswa dalam belajar dapat terselesaikan dengan baik sehingga hasil belajar yang dicapai oleh siswa akan maksimal (Sari, 2015: 1671).

Salah satu faktor yang mempengaruhi hasil belajar siswa yaitu kegiatan belajar siswa. Belajar ialah suatu proses usaha yang dilakukan seseorang untuk memperoleh suatu perubahan tingkah laku yang baru secara keseluruhan, sebagai hasil pengalamannya sendiri dalam interaksi lingkungannya (Slameto, 2010: 2). Belajar pada dasarnya merupakan proses dan usaha untuk mendapatkan sebuah perubahan, baik dari sisi pengetahuan, sikap, maupun keterampilan. Hasil belajar akan mempengaruhi banyak aspek pada siswa, baik pengetahuan, sikap, maupun keterampilannya yang kemudian akan berdampak pada pertumbuhan dan perkembangannya bahkan dapat 
berdampak pada kepribadian dan karakternya. Hal ini dikarenakan keberhasilan pendidikan dapat dilihat dari kualitas pendidikan yang ada, dimana kualitas pendidikan itu meliputi kualitas proses maupun kualitas lulusan (Maesaroh, 2013: 151). Sejalan dengan pendapat Susanto (2016: 5) menyatakan bahwa hasil belajar yaitu perubahanperubahan yang terjadi pada diri siswa, baik yang menyangkut aspek kognitif, afektif, dan psikomotor sebagai hasil dari kegiatan belajar. Pencapaian hasil belajar yang berkualitas merupakan salah satu tujuan pembelajaran berbagai bidang mata pelajaran. Demikian pula pada mata pelajaran matematika yang merupakan pokok bahasan dalam penelitian ini. Hasil belajar pada mata pelajaran matematika yang optimal merupakan tolak ukur keberhasilan siswa dalam belajar mata pelajaran matematika.

Berdasarkan hasil wawancara yang dilakukan oleh peneliti dan guru matematika kelas IV di SD Negeri 1 Pejagoan hasil belajar matematika siswa kelas IV belum memuaskan, karena masih terdapat siswa yang nilainya belum mencapai Kriteria Ketuntasan Minimum (KKM) yaitu 75. Banyak siswa yang berminat untuk mengikuti bimbingan belajar di luar sekolah. Sebagian siswa yang mengikuti bimbingan belajar bertujuan untuk mengatasi kesulitan dalam belajar. Akan tetapi menurut guru matematika kelas IV, siswa yang mengikuti bimbingan belajar di luar sekolah dengan siswa yang tidak mengikuti bimbingan belajar di luar sekolah memiliki perbedaan. Setiap siswa memiliki daya tangkap dan karakteristik yang berbeda-beda dalam tingkat keaktifannya. Beberapa siswa yang tidak mengikuti bimbingan belajar di luar sekolah justru terlihat lebih aktif dan cepat ketika memahami materi pelajaran matematika saat diajarkan oleh guru kelas jika dibandingkan dengan siswa yang mengikuti bimbingan belajar di luar sekolah. Artinya, siswa yang mengikuti bimbingan belajar di luar sekolah tidak selalu lebih unggul dengan siswa yang tidak mengikuti bimbingan belajar di luar sekolah terhadap hasil nilai matematika

Berdasarkan penjelasan di atas, pemasalahan dalam penelitian ini adalah: Apakah hasil belajar siswa yang mengikuti bimbingan belajar di luar sekolah lebih baik dari siswa yang tidak mengikuti bimbingan belajar di luar sekolah terhadap hasil belajar matematika siswa kelas IV SDN se-Kecamatan Pejagoan tahun ajaran 2019/2020?

Berdasarkan permasalahan di atas maka tujuan dari penelitian ini yaitu : Membuktikan hasil belajar siswa yang mengikuti bimbingan belajar di luar sekolah lebih baik dari siswa yang tidak mengikuti bimbingan belajar di luar sekolah terhadap hasil belajar matematika siswa kelas IV SDN se-Kecamatan Pejagoan tahun ajaran 2019/2020.

\section{METODE PENELITIAN}

Desain penelitian yang digunakan yaitu penelitian kuantitatif dengan metode komparasi. Kata komparasi dalam bahasa Inggris comparation yang berarti perbandingan. Makna dari kata tersebut memnunjukkan perbandingan kondisi yang ada di dua tempat, apakah kondisi tersebut sama atau ada perbedaan, dan kalau ada perbedaan, kondisi di tempat mana yang lebih baik (Arikunto, 2013: 6) .

Populasi pada penelitian ini yaitu semua siswa kelas IV SDN di Kecamatan Pejagoan yang berjumlah 28 sekolah dasar. Pengambilan sampel dilakukan dengan teknik cluster random sampling. Sampel yang digunakan dalam penelitian ini adalah 10 SDN di Kecamatan Pejagoan. Jumlah sampel dalam penelitian ini yaitu 263 siswa di sepuluh SDN di Kecamatan Pejagoan. Pengambilan sampel dilakukan secara random menggunakan aplikasi SPSS versi 16. Jumlah sampel yang mengikuti bimbingan belajar di luar sekolah berjumlah 103 siswa dan sampel yang tidak mengikuti bimbingan belajar di luar sekolah berjumlah 160 siswa.

Teknik pengumpulan data yang digunakan dalam penelitian ini yaitu ujian (tes). Tes yang digunakan dalam penelitian ini yaitu tes matematika kelas IV dengan materi semester 1. Tes dalam penelitian ini berupa soal pilihan ganda. Sebelum digunakan, tes 
diuji validitasnya terlebih dahulu. Pengujian validitas dilakukan di dua SDN di Kecamatan Pejagoan.

Uji prasyarat data yang digunakan adalah uji homogenitas dan normalitas. Hal ini sesuai dengan pendapat Riduwan (2011: 184) bahwa sebelum melakukan pengujian, data harus homogen artinya data yang dibandingkan (dikomparasikan) sejenis (bersifat homogen) sehingga perlu dilakukan uji homogenitas. Selain itu, dalam uji perbedaan data yang digunakan juga harus berdistribusi normal.

\section{HASIL DAN PEMBAHASAN}

Hasil uji normalitas sebaran terhadap hasil belajar matematika siswa yang mengikuti bimbingan belajar di luar sekolah menghasilkan nilai sig $=0,063$ ( $\operatorname{sig}>0,05)$. Hasil uji berdasarkan kaidah menujukkan hasil belajar matematika siswa yang mengikuti bimbingan belajar di luar sekolah adalah normal. Hasil uji normalitas sebaran terhadap hasil belajar matematika siswa yang tidak mengikuti bimbingan belajar di luar sekolah menghasilkan nilai sig $=0,062$ ( $\mathrm{sig}>0,05$ ). Hasil uji berdasarkan kaidah menujukkan hasil belajar matematika siswa yang tidak mengikuti bimbingan belajar di luar sekolah adalah normal.

Tabel 4.1 Hasil Analisis Uji Normalitas Hasil Belajar Matematika Siswa yang Mengikuti Bimbingan Belajar di Luar Sekolah

\section{Tests of Normality}

\begin{tabular}{lllllllll}
\hline & $\begin{array}{l}\text { Bimbingan } \\
\text { Belajar di Luar }\end{array}$ & \multicolumn{3}{c}{ Kolmogorov-Smirnov $^{\mathrm{a}}$} & \multicolumn{3}{c}{ Shapiro-Wilk } \\
$\begin{array}{l}\text { Sekolah } \\
\text { Hasil Belajar } \\
\text { Matematika }\end{array}$ & $\begin{array}{l}\text { Siswa yang } \\
\text { mengikuti } \\
\text { bimbingan belajar } \\
\text { di luar sekolah }\end{array}$ & .085 & 103 & .063 & .967 & 103 & .011 \\
\hline
\end{tabular}

Tabel 4.2 Hasil Analisis Uji Normalitas Hasil Belajar Matematika Siswa yang Tidak Mengikuti Bimbingan Belajar di Luar Sekolah

Tests of Normality

\begin{tabular}{|c|c|c|c|c|c|c|c|}
\hline \multirow{4}{*}{$\begin{array}{l}\text { Hasil Belajar } \\
\text { Matematika }\end{array}$} & \multirow{2}{*}{$\begin{array}{l}\text { Bimbingan Belajar Di } \\
\text { Luar Sekolah }\end{array}$} & \multicolumn{3}{|c|}{ Kolmogorov-Smirnov ${ }^{\mathrm{a}}$} & \multicolumn{3}{|c|}{ Shapiro-Wilk } \\
\hline & & Statistic & $d f$ & Sig. & Statistic & $d f$ & Sig. \\
\hline & Siswa yang tidak & & & & & & \\
\hline & $\begin{array}{l}\text { mengikuti bimbingan } \\
\text { belajar di luar } \\
\text { sekolah }\end{array}$ & .069 & 160 & .062 & .984 & 160 & .054 \\
\hline
\end{tabular}

Tabel 4.3 Hasil Analisis Uji Homogenitas Hasil Belajar Matematika siswa yang MengikutiBimbingan Belajar di Luar Sekolah dan Siswa yang tidak Mengikuti Bimbingan Belajar di Luar Sekolah

Test of Homogeneity of Variances

\begin{tabular}{rrrr}
\hline Hasil Belajar Matematika & & & \\
\hline Levene Statistic & $\mathrm{df1}$ & $\mathrm{df2}$ & \multicolumn{1}{c}{ Sig. } \\
\hline 1.507 & 1 & 261 & .221 \\
\hline
\end{tabular}


Hasil analisis uji homogenitas antara hasil belajar matematika siswa yang mengikuti bimbingan belajar di luar sekolah dan siswa yang tidak mengikuti bimbingan belajar di luar sekolah memiliki nilai sig =0,221 ( $\mathrm{sig}>0,05$ ). Oleh karena itu, data hasil belajar matematika siswa kelas IV sekolah dasar memiliki varian yang sama atau homogen.

Tabel 4.4 Output Pertama Hasil Analisis Uji Independent Sample T-Test

\section{Group Statistics}

\begin{tabular}{lllllr}
\hline & $\begin{array}{l}\text { Bimbingan Belajar di } \\
\text { Luar Sekolah }\end{array}$ & $\mathrm{N}$ & Mean & $\begin{array}{c}\text { Std. } \\
\text { Deviation }\end{array}$ & $\begin{array}{c}\text { Std. Error } \\
\text { Mean }\end{array}$ \\
$\begin{array}{l}\text { Hasil Belajar } \\
\text { Matematika }\end{array}$ & $\begin{array}{l}\text { Siswa yang mengikuti } \\
\text { bimbingan belajar di } \\
\text { luar sekolah } \\
\text { siswa yang tidak } \\
\text { mengikuti bimbingan } \\
\text { belajar di luar sekolah }\end{array}$ & 103 & 75.37 & 12.901 & 1.271 \\
\hline
\end{tabular}

Output ini menjelaskan tentang statistik antara hasil belajar matematika siswa yang mengikuti bimbingan belajar di luar sekolah dan siswa yang tidak mengikuti bimbingan belajar di luar sekolah. Untuk siswa yang mengikuti bimbingan belajar di luar sekolah berjumlah 103 siswa dan untuk siswa yang tidak mengikuti bimbingan belajar di luar sekolah berjumlah 160 siswa. Rata-rata hasil belajar matematika siswa kelas IV sekolah dasar yang mengikuti bimbingan belajar di luar sekolah adalah 75,37 sedangkan hasil belajar matematika siswa kelas IV sekolah dasar yang tidak mengikuti bimbingan belajar di luar sekolah adalah 42,74. Standar deviasi hasil belajar matematika siswa kelas IV sekolah dasar yang mengikuti bimbingan belajar di luar sekolah adalah 12,901 dan standar deviasi siswa yang tidak mengikuti bimbingan belajar di luar sekolah adalah adalah 14.863. Standar error mean hasil belajar matematika siswa kelas IV sekolah dasar yang mengikuti bimbingan belajar di luar sekolah adalah 1,271 dan standar mean hasil belajar matematika siswa yang tidak mengikuti bimbingan belajar di luar sekolah adalah 1,175 .

Tabel 4.5 Output Kedua Hasil Analisis Uji Independent Sample T-Test

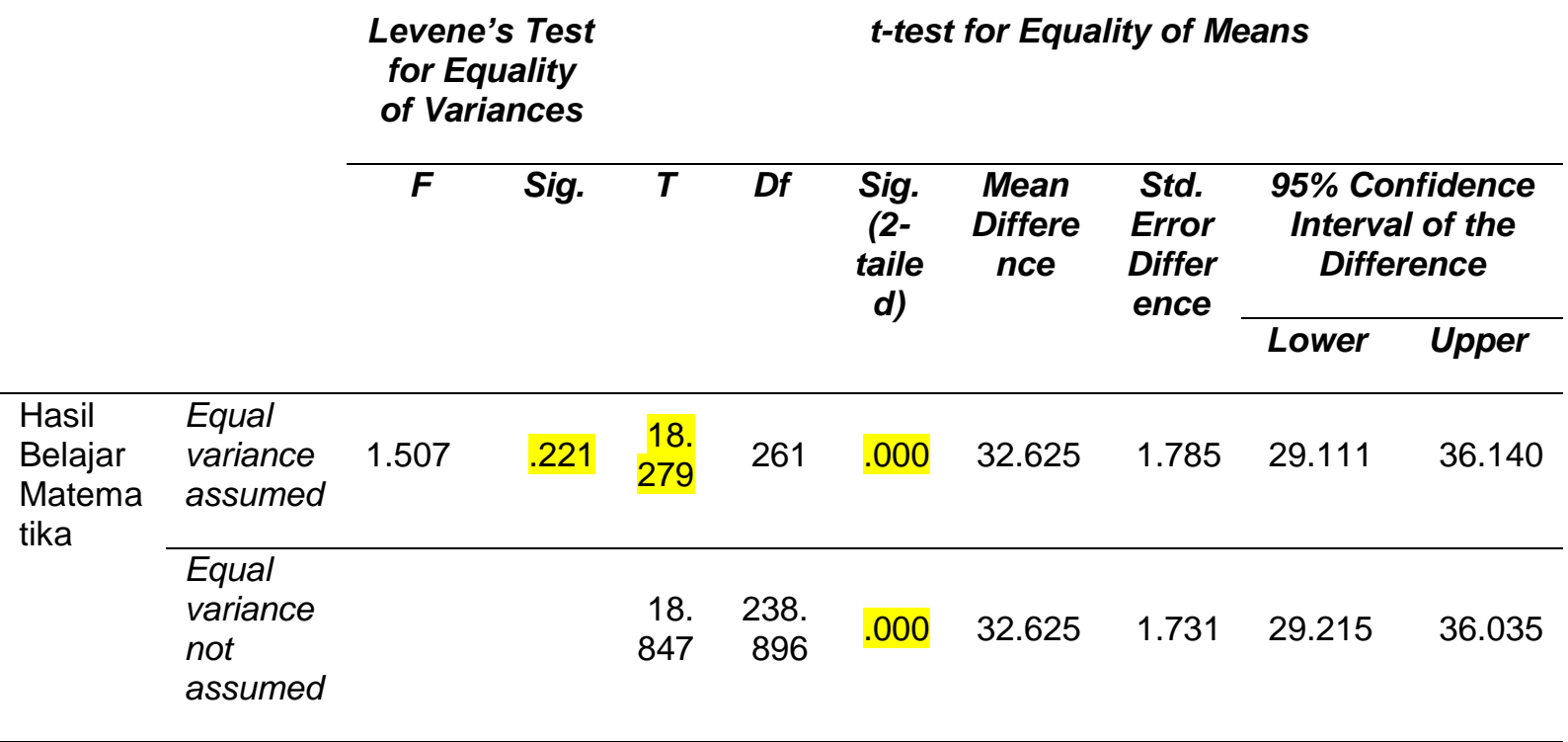


Jika data dalam penelitian memiliki varian yang sama atau homogen, maka uji t yang akan dilakukan yaitu equal variances assumed. Untuk pengambilan keputusan uji independent sample $t$-test dalam penelitian ini dapat dilihat pada kolom signifikansi equal variances assumed. Jika signifikansi kurang dari 0,05, maka kesimpulannya adalah ada perbedaan hasil belajar matematika siswa kelas IV sekolah dasar yang mengikuti bimbingan belajar di luar sekolah dan siswa kelas IV sekolah dasar yang tidak mengikuti bimbingan belajar di luar sekolah.

Hasil penelitian ini juga sesuai dengan penelitian yang dilakukan oleh Amalia, D (2018) yang menyatakan bahwa terdapat perbedaan antara rata-rata hasil belajar siswa pada mata pelajaran matematika untuk siswa yang mengikuti bimbingan belajar di luar sekolah dengan rata-rata hasil belajar siswa yang tidak mengikuti bimbingan belajar di luar sekolah. Rata-rata (mean) siswa yang mengikuti bimbingan belajar di luar sekolah adalah 86,96 dan untuk hasil siswa yang tidak mengikuti bimbingan belajar di luar sekolah adalah 83,59.

Selain itu hasil penelitian ini juga diperkuat dengan penelitian yang dilakukan oleh Noviyanti, A dan Rizki, R (2019:113) yang menyatakan bahwa hasil prestasi belajar biologi siswa SMA Negeri 8 Banda Aceh yang mengikuti bimbingan belajar di luar sekolah lebih meningkat dan lebih baik dibandingkan dengan siswa yang tidak mengikuti bimbingan belajar di luar sekolah.

Berdasarkan uraian di atas, dapat disimpulkan bahwa hasil penelitian ini telah sesuai dengan teori yang ada dan didukung pula dengan penelitian yang relevan, maka hasil penelitian ini adalah bahwa bimbingan belajar di luar sekolah memberikan pengaruh yang lebih baik tehadap hasil belajar matematika siswa, yang berarti perbedaan antara siswa yang mengikuti bimbingan belajar di luar sekolah dengan siswa yang tidak mengikuti bimbingan belajaar di luar sekolah terhadap hasil belajar matematika siswa kelas IV SDN se-Kecamatan Pejagoan adalah signifikan dan dapat diberlakukan untuk populasi.

\section{SIMPULAN DAN SARAN}

Berdasarkan hasil penelitian diperoleh simpulan bahwa ada perbedaan antara siswa yang mengikuti bimbingan belajar di luar sekolah dengan siswa yang tidak mengikuti bimbinan belajar di luar sekolah terhadap hasil belajar matematika siswa kelas IV SDN se-Kecamatan Pejagoan tahun 2019/2020. Rata-rata hasil belajar matematika siswa yang mengikuti bimbingan belajar di luar sekolah adalah 75,37, sedangkan ratarata hasil belajar matematika siswa yang tidak mengikuti bimbingan belajar di luar sekolah adalah 42,74. Berdasarkan hasil rata-rata tersebut, bimbingan belajar di luar sekolah memberikan pengaruh yang lebih baik terhadap hasil belajar matematika siswa kelas IV SDN se-Kecamatan Pejagoan tahun ajaran 2019/2020.

Berdasarkan simpulan yang telah dipaparkan, peneliti memberikan beberapa saran: (1) bagi guru, hendaknya lebih memahami kondisi siswa yang mempunyai tingkat kecerdasan yang berbeda-beda, sehingga guru harus tepat dalam menentukan metode mengajar apa yang tepat untuk digunakan mengajar. menghimbau siswa yang mengikuti bimbingan belajar di luar sekolah agar lebih serius dan bersungguh-sungguh dalam mengikuti bimbingan belajar sehingga dapat meningkatkan lagi hasil belajar matematikanya; (2) bagi sekolah, diharapkan untuk meningkatkan kualitas dari segi siswa dengan memotivasi siswa agar lebih aktif dalam belajar dan meninkatkan sarana dan prasarana pembelajaran yang mendukung; (3) bagi peneliti selanjutnya dapat melakukan penelitian terkait dengan faktor lainya yang dapat mempengaruhi hasil belajar matematika dan dapat menjadi acuan dalam penelitian komparasi serta diharapkan mencari sumber referensi lainnya agar nanti penelitiannya akan jauh lebih baik. 


\section{DAFTAR PUSTAKA}

Amalia, D. (2018). Pengaruh Keikutsertaan Bimbingan Belajar Terhadap Hasil Belajar Siswa Kelas V SDIT Salsabila 3 Banguntapan. Skripsi Tidak Dipublikasikan. Universitas Islam Negeri Sunan Kalijaga Yogyakarta.

Arikunto, S. (2013). Prosedur Penelitian: Suatu Pendekatan Praktik, Jakarta: Rineka Cipta.

Mesaroh, S. (2013). Peranan Metode Pembelajaran Terhadap Minat dan Prestasi Belajar Pendidikan Agama Islam. Jurnal Kependidikan, 1 (1), 150-168.

Noviyanti, A \& Rizki, R. (2019). Perbandingan Siswa Les dan Tidak Les Terhadap Prestasi Belajar Biologi di Sma Negeri 8 Banda Aceh. Jurnal BIO natural, 6(1), $102-114$.

Nurlinggasari, D. (2017). Hubungan Bimbingan Belajar di Luar Sekolah Dan Motivasi Belajar Dengan Prestasi Belajar Biologi. Skripsi Tidak Dipublikasikan. Universitas Lampung.

Nusantari, C, D,G. (2011). Persepsi Siswa Kelas Xii Sma Negeri Terhadap Lembaga Bimbingan Belajar di Kota Semarang. Skripsi Tidak Dipublikasikan. Universitas Negeri Semarang.

Prasetya, I, Winarno, R., \& Praharesti, E. (2013). Bimbingan Belajar Efektif Untuk Meningkatkan Kebiasaan Belajar pada Siswa Kelas VII. Kajian IImiah Psikologi, 2 (1), 1-4.

Riduwan. (2011). Dasar-dasar Statistika. Bandung: Alfabeta.

Sari, Y.W. (2015). Pengaruh Bimbingan Belajar Terhadap Hasil Belajar Matematika Siswa Kelas IV di Sekolah Dasar. Jurnal PGSD, 3 (2), 1670-1680.

Sisdiknas. 2011. Undang-Undang Sistem Pendidikan Nasional Nomor 20 Tahun 2003. Sinar Grafika, Jakarta.

Slameto. (2010). Belajar dan Faktor-Faktor yang Mempengaruhi. Jakarta: PT. Rineka Cipta.

Susanto, A. (2016). Teori Belajar dan Pembelajaran di Sekolah Dasar. Jakarta: Prenadamedia Group. 